\title{
Practice Patterns for Prophylaxis and Treatment of Venous Thromboembolism in German Cancer Patients
}

\author{
Axel Matzdorffa Bettina Ledig ${ }^{b} \quad$ Markus Stuecker $^{c}$ Hanno Riess $^{d}$ \\ a Department of Internal Medicine II, Asklepios Hospital Uckermark, Schwedt/Od., Germany; \\ ${ }^{b}$ LEO Pharma GmbH, Neu-Isenburg, Germany; \\ 'Department of Dermatology, St. Josef Hospital, Ruhr University of Bochum, Bochum, Germany; \\ d Medical Clinic Hematology/Oncology, Charité, Campus Charité Mitte, Berlin, Germany
}

\section{Keywords}

Cancer-associated venous thromboembolism .

Health services research

\section{Summary}

Background: Venous thromboembolism (VTE) is a serious threat for cancer patients. Guidelines recommend low-molecular-weight heparin (LMWH) for prophylaxis and treatment, but it is unknown to what extent specialists adhere to these recommendations. This survey assesses the current approach to patients with cancer-associated VTE in Germany. Materials and Methods: A questionnaire was sent out to members of the DGHO (Deutsche Gesellschaft für Hämatologie und Onkologie), the BNHO (Berufsverband Niedergelassener Hämatologen und Onkologen) and the DGP (Deutsche Gesellschaft für Phlebologie). For most questions, more than 1 answer was possible; therefore, the total sum of percentages may exceed $100 \%$. Results: 275 specialists responded. $76 \%$ of them treat acute VTE with LMWH while $22 \%$ switch to oral treatments (vitamin $\mathrm{K}$ antagonists (VKAs) or non-VKA oral anticoagulants (NOACs)) during the acute phase. For the next 3-6 months, $55 \%$ of the specialists continue LMWH, while $31 \%$ switch to VKAs and $33 \%$ to NOACs. Among those who continue LMWH for 3-6 months, $37 \%$ continue at the full dose, $26 \%$ reduce to $75 \%$ of the initial dose, and $40 \%$ even to $50 \%$. Important factors guiding treatment decisions were the need for injections and the availability of a partner/spouse (LMWH), the need for laboratory controls (VKAs), and the number of other oral medications (NOACs). Conclusion: This survey reveals that practice patterns often do not follow the guideline recommendations with respect to the use of LMWH for long-term treatment of VTE in cancer patients.

(C) 2016 S. Karger GmbH, Freiburg

\section{Introduction}

Venous thromboembolism (VTE) is a frequent and serious complication of cancer. Without prophylaxis, up to $8 \%$ of ambulatory [1] and almost $20 \%$ of hospitalized cancer patients develop VTE [2]. The overall risk is 4-7-fold higher than in non-cancer patients. This high incidence comes from a multitude of risk factors in cancer patients, including frequent surgeries, immobility, advanced age, and prothrombotic medications (e.g., hormonal therapies, angiogenesis inhibitors, thalidomide and its derivatives). In addition, tumors activate coagulation factors and platelets to a variable degree, which supports the growth and spread of tumor cells, thereby creating a positive feedback loop $[3,4]$. VTE in cancer patients is associated with a poorer prognosis compared to cancer patients without VTE [5-7].

The prevention and treatment of cancer-associated VTE has become an important issue in the daily care of cancer patients. Several national and international evidence-based guidelines on the prevention and treatment of cancer-associated VTE have been published to support clinicians working in the field [8-11]. These guidelines uniformly recommend thromboprophylaxis for hospitalized cancer patients, while routine thromboprophylaxis is not recommended for ambulatory patients. If VTE occurs, treatment recommendations differ between non-cancer and cancer patients. The former usually receive a rapid-acting, parenteral anticoagulant (unfractionated heparin (UFH), low-molecularweight heparin (LMWH), or fondaparinux) overlapping with and followed by an oral vitamin $\mathrm{K}$ antagonist (VKA). The new nonVKA oral anticoagulants (NOACs) have also been approved for this indication. The treatment of cancer-associated VTE is different in the way that LMWHs should be given initially and as longterm treatment because of their improved efficacy over VKAs.

\section{KARGER \\ Fax +497614520714

\section{() 2016 S. Karger GmbH, Freiburg}

2296-5270/16/0394-0194\$39.50/0
Axel Matzdorff, MD, PhD

Department of Internal Medicine II

Asklepios Hospital Uckermark

Auguststr. 23, 16303 Schwedt/Od., Germany

a.matzdorff@mx.uni-saarland.de 
The use of NOACs is currently not recommended for patients with malignancy and VTE.

This preference for LMWH is based on 4 studies that date back to the 1990s or early 2000s. The LITE study started in 1994 [12], CANTHANOX in 1995 [13], CLOT in 1999 [14], and the ONCENOX study in 2001 [15]. The treatment of cancer patients has changed fundamentally since then. Today, the majority of cancer patients are treated in the ambulatory care setting. Patients survive longer and quality of life and convenience of treatment are major issues in daily care. Several studies indicate that the impact of VTE guidelines on clinical practice is limited $[16,17]$. This is particularly true for the use of LMWHs in the long-term treatment of cancer-associated VTE. Many patients receive VKAs instead, and if LMWHs are given, they are often underdosed or terminated prematurely [18-29]. With the advent of NOACs, the preference of the guidelines for LMWHs over any of these newer agents will be further challenged. It is likely that many patients will prefer taking a pill that does not require frequent blood testing (international normalized ratio (INR) in case of VKA) or daily subcutaneous (s.c.) injections (LMWH) [30].

For any future recommendations, it is important to know: Which cancer patients already receive thromboprophylaxis and which of them do not? Who diagnoses VTE when it occurs and who is in charge of the anticoagulant treatment? Which guideline recommendations have already been implemented in real-world oncology care, which of them have not, and why? The purpose of this study was to assess all these different aspects of VTE treatment in cancer patients in Germany.

\section{Materials and Methods}

This was a cross-sectional survey on the attitudes of physicians towards the prophylaxis and treatment of cancer-associated VTE.

In a first step, a questionnaire was drafted by the authors. This questionnaire was discussed with specialists in hematology/oncology and VTE treatment in several meetings and further adapted to the clinical practice. The final questionnaire contained mainly multiple-choice questions and is available as an online supplement.

In January 2014, the questionnaire was sent out by mail or electronically to all members of the DGHO (Deutsche Gesellschaft für Hämatologie und Onkologie), the BNHO (Berufsverband Niedergelassener Hämatologen und Onkologen), and the DGP (Deutsche Gesellschaft für Phlebologie). Data lock was April 1.

Descriptive analysis of the data was carried out according to a pre-established analysis plan. The collected data were analyzed using the Statistical Package for the Social Sciences software (SPSS version 22.0). In case of single-choice questions, a Chi squared $\left(\chi^{2}\right)$ test was carried out to assess the independence of the distribution of the answers relative to the participant subgroups. For multiple-choice questions, each answer was assessed independently by means of Fisher's exact test on a $2 \times 2$ contingency table. All tests were 2 -sided at a $5 \%$ level of significance.

For most questions, more than 1 answer was possible. In these cases, the sum of percentages may exceed $100 \%$. Not all respondents answered each question. When the sum of answers was smaller than the number of completed questionnaires, relative percentages were calculated based on the number of evaluable answers.
Table 1. Characteristics of the responding physicians

\section{Physician's specialty}

Internal medicine, hematology, oncology

Internal medicine (not hematologists/oncologists)

Angiology

Phlebology

Additional qualification in hemostasis

Other specialties

Physician's primary location of medical service

Hospital

Practice

Other

Start of practicing medicine

Before 1980

1980-1990

$1991-2000$

2001-2010

After 2010

\begin{tabular}{rr}
214 & 78.4 \\
27 & 9.9 \\
7 & 2.6 \\
27 & 9.9 \\
22 & 8.1 \\
49 & 17.9 \\
& \\
107 & 39.1 \\
136 & 59.5 \\
9 & 3.3 \\
& \\
18 & 6.6 \\
117 & 43.0 \\
100 & 36.8 \\
36 & 13.2 \\
1 & 0.4 \\
\hline
\end{tabular}

\section{Results}

A total of 4,627 questionnaires were sent out between January and February 2014. 275 (5.9\%) of them were completed and available for analysis. Most of the responding physicians were hematologists/oncologists or angiologists/phlebologists. The majority worked in ambulatory patient care and had been practicing medicine for more than 20 years (table 1). 58.3\% stated to see between 1 case of cancer-associated VTE per month and 1 case per week; $28.4 \%$ see even more than 1 case per week. $38.3 \%$ of the hematologists/oncologists reported that they routinely educate their patients about the risk and symptoms of VTE (this is the only analysis where non-hematologists/oncologists were censored because nonhematologists/oncologists usually do not educate patients with regard to oncology treatments).

\section{Prophylaxis of VTE}

For hospitalized cancer patients, $67.8 \%$ of the physicians routinely offer thromboprophylaxis unless contraindicated. In the ambulatory care setting, 5.3\% offer thromboprophylaxis routinely. Among those physicians who offer thromboprophylaxis only to ambulatory patients with risk factors, $58.6 \%$ give it to multiple myeloma patients, $45.0 \%$ to pancreatic cancer patients, and $35.1 \%$ base their decision on a combination of tumor type and performance status. Only $13 \%$ of the respondents utilized the Khorana score [1], a prediction score that assesses the risk of VTE in ambulatory patients with cancer. Most physicians felt that a history of prior VTE was the most relevant risk factor for VTE in cancer patients, followed by tumor type and mobility/performance status (table 2). 
Table 2. Factors considered relevant for VTE risk in cancer patients (more than 1 answer allowed)

\begin{tabular}{llc}
\hline & $\mathrm{n}$ & $\%$ \\
\hline Age & 155 & 57.4 \\
Tumor type & 242 & 89.6 \\
Tumor stage & 146 & 57.8 \\
Mobility/ECOG & 242 & 89.6 \\
Recent surgery & 209 & 77.4 \\
Medication & 230 & 85.2 \\
Social factors & 22 & 8.1 \\
$\quad$ (education, occupation) & & \\
History of VTE & 259 & 95.9 \\
\hline
\end{tabular}

ECOG $=$ Eastern Cooperative Oncology Group,

$\mathrm{VTE}=$ venous thromboembolism

Table 3. Who performs diagnostic workup in cancer patients with suspected VTE (more than 1 answer allowed)?

\begin{tabular}{lrl}
\hline & $\mathrm{n}$ & $\%$ \\
\hline Physician himself & 100 & 37.2 \\
Patient is sent to a hospital with in- and outpatient & 86 & 32.0 \\
$\quad$ diagnostic facilities & & \\
Patient is referred to a vascular care specialist & 91 & 33.8 \\
Patient is referred to a radiologist (ambulatory care) & 49 & 18.2 \\
Patient is referred to a hematologist/oncologist & 1 & 0.4 \\
Patient is referred to another specialist (not specified) & 16 & 5.9 \\
\hline
\end{tabular}

Table 4. Initial treatment (more than 1 answer allowed)

\begin{tabular}{lrl}
\hline For the initial treatment of newly diagnosed VTE, ... & $\mathrm{n}$ & $\%$ \\
\hline I give only LMWH & 206 & 76.3 \\
$\begin{array}{l}\text { I initially give LMWH and switch to an oral } \\
\text { anticoagulant soon }\end{array}$ & 60 & 22.2 \\
\begin{tabular}{l} 
I refer my patient to another physician who decides \\
\hline
\end{tabular} & 7 & 2.6 \\
\hline
\end{tabular}

\section{Diagnosis and Acute Treatment of VTE}

When a patient has symptoms of VTE, most of the treating physicians perform the diagnostic workup themselves, followed by sending the patient to a hospital with special in- and outpatient diagnostic facilities, or to a vascular care specialist (table 3 ). The diagnostic workup is triggered by symptoms in $85 \%$ of patients; thus, $15 \%$ of the patients are asymptomatic and VTE is an incidental finding. The Wells score, a clinical prediction score that assesses the probability of VTE [31], is used in $9 \%$ of symptomatic patients. For initial treatment, $76.3 \%$ of the physicians give LMWH only; $22.2 \%$ start with an LMWH but switch to an oral anticoagulant within 3-4 weeks (table 4). After the initial diagnosis and therapy, $68.6 \%$ of the responding physicians stay in charge of the VTE management, which means that they are responsible for prescribing, monitoring, and dosing the anticoagulants; $39.0 \%$ refer their patients to the family physician and $15.2 \%$ to another specialist.
Table 5. Duration, dose, and type of secondary prophylaxis (more than 1 answer allowed)

\begin{tabular}{|c|c|c|}
\hline & $\mathrm{n}$ & $\%$ \\
\hline \multicolumn{3}{|c|}{ How long do you give secondary prophylaxis? (all types of anticoagulants) } \\
\hline Less than 1 month & 8 & 3.1 \\
\hline Up to 3 months & 71 & 27.5 \\
\hline Up to 6 months & 145 & 56.2 \\
\hline More than 6 months & 187 & 72.5 \\
\hline I am not in charge of therapy & 35 & 13.6 \\
\hline \multicolumn{3}{|c|}{ Do you switch your patient to OAs for secondary prophylaxis? } \\
\hline I do not give OAs & 127 & 55.0 \\
\hline I switch to VKAs & 71 & 30.7 \\
\hline I switch to NOACs & 77 & 33.3 \\
\hline \multicolumn{3}{|l|}{ When do you switch to OA? } \\
\hline After 1 month & 41 & 36.9 \\
\hline After 3 months & 26 & 23.4 \\
\hline After 6 months & 21 & 18.9 \\
\hline \multicolumn{3}{|c|}{ In case you give LMWHs for secondary prophylaxis: which dose? } \\
\hline I give full dose (100\%) & 79 & 37.1 \\
\hline I reduce to $75 \%$ & 55 & 25.8 \\
\hline I reduce to $50 \%$ & 86 & 40.4 \\
\hline \multicolumn{3}{|c|}{ When do you reduce the LMWH dose? } \\
\hline I do not reduce the dose & 86 & 38.6 \\
\hline After 1 month & 50 & 22.4 \\
\hline After 3 months & 70 & 31.4 \\
\hline Other & 28 & 12.6 \\
\hline
\end{tabular}

$\mathrm{OA}=$ Oral anticoagulant, $\mathrm{VKA}=$ vitamin $\mathrm{K}$ antagonist, $\mathrm{NOAC}=$ nonVKA oral anticoagulant, LMWH = low-molecular-weight heparin.

Table 6. Type of prolonged secondary prophylaxis (more than 1 answer allowed)

\begin{tabular}{lll}
\hline $\begin{array}{l}\text { Long-term anticoagulation beyond } \\
\text { secondary prophylaxis (after 6-12 months) }\end{array}$ & $\mathrm{n}$ & $\%$ \\
\hline LMWH alone & 78 & 38.0 \\
VKA & 93 & 45.4 \\
NOAC & 81 & 39.5
\end{tabular}

LMWH = Low-molecular-weight heparin, VKA = vitamin $\mathrm{K}$ antagonist,

NOAC $=$ non-VKA oral anticoagulant.

\section{Secondary Prophylaxis (Anticoagulation after Acute Phase for} 3-6 Months)

Most physicians offer anticoagulation for 3-6 months. When using an LMWH, $40.4 \%$ reduce the dose to $50 \%$ of the initial full therapeutic dose. $30.7 \%$ of the respondents switch to a VKA, $33.3 \%$ to a NOAC (table 5).

\section{Long-Term Anticoagulation beyond 3-6 Months}

$69 \%$ of the physicians responded that they offer long-term anticoagulant treatment for as long as cancer is active; most patients are then switched to a VKA or a NOAC (table 6). 
Fig. 1. Factors

considered relevant for prescribing LMWH vs. VKA vs. NOAC.

$\mathrm{VTE}=$ Venous thromboembolism, INR = international normalized ratio, LMWH = low-molecular-weight heparin, $\mathrm{VKA}=$ vitamin $\mathrm{K}$ antagonist,

$\mathrm{NOAC}=$ non-VKA oral anticoagulant.

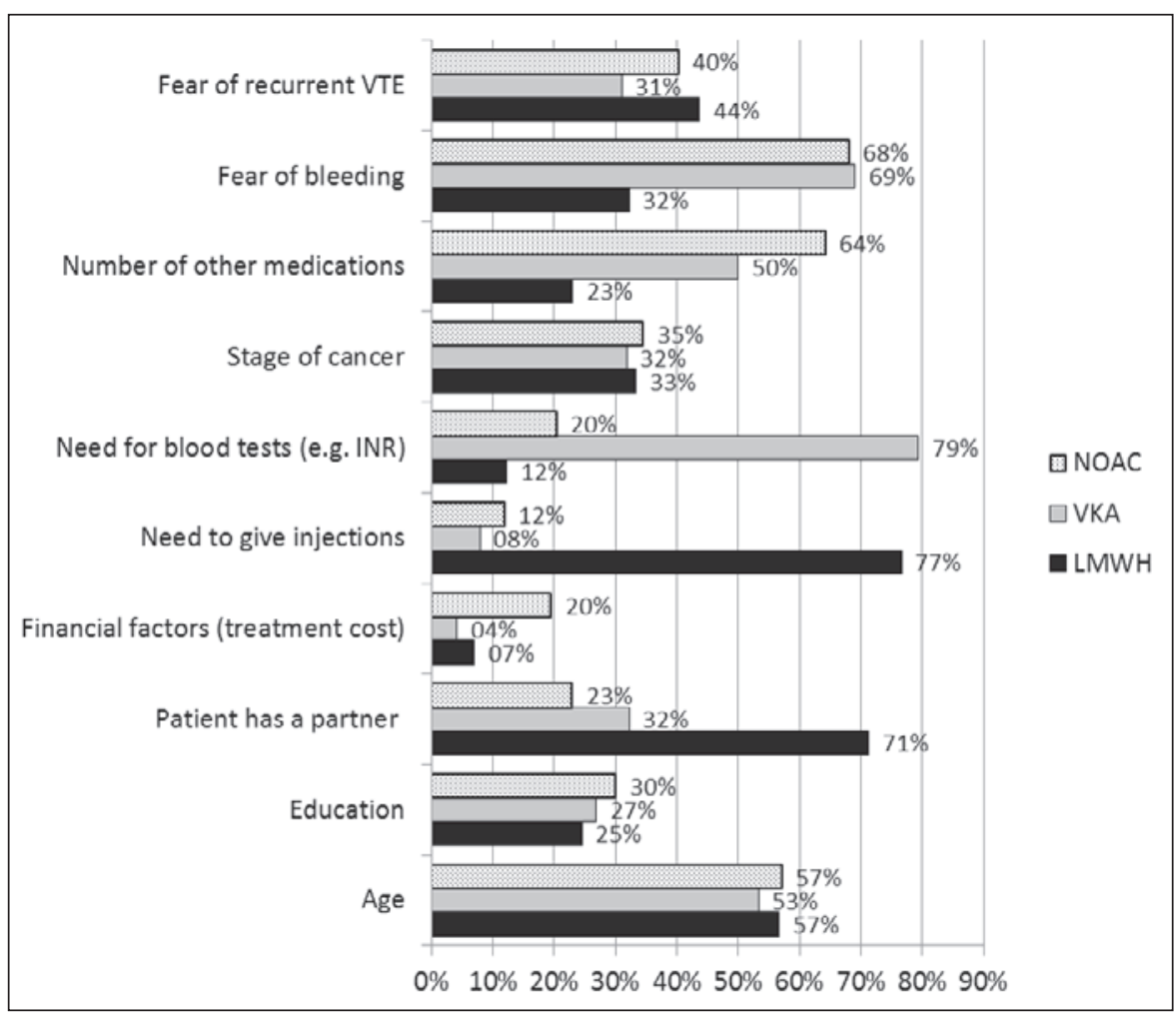

\section{Adherence}

Factors considered by physicians as relevant for treatment adherence of their patients differed between LMWH, VKAs, and NOACs (fig. 1). For LMWH, the need of injections and the availability of a partner to perform the injections were considered most relevant, while the need for blood tests and fear of bleeding dominated in case of the VKAs and the number of comedications and fear of bleeding in case of NOACs. Fear of serious hemorrhage was more than 2 times higher with VKAs and NOACs than with LMWH.

\section{Discussion}

This study was designed to assess the daily practice of VTE prophylaxis and treatment in cancer patients in Germany. A questionnaire was sent out to German hematologists/oncologists and vascular medicine specialists. The results show that VTE prophylaxis and initial treatment with LMWH follow the guideline recommendations while the dose and type of the anticoagulant for secondary prophylaxis and long-term treatment varied substantially.

\section{Did the Survey Reach Its Intended Target Group?}

In Germany, cancer care is divided between hospital-based and ambulatory practice-based hematologists/oncologists. In addition, many patients with cancer-associated VTE are treated by vascular medicine specialists (angiologists, phlebologists). Almost all Ger- man hematologists/oncologists are members of either the DGHO or the BNHO (or both) and many vascular medicine specialists are members of the DGP. By sending the questionnaire to all members of these 3 organizations, we hoped to reach the intended target group. Other medical subspecialties (e.g. vascular surgeons and general internists) were not addressed in order to limit the survey to those physicians with the highest likelihood to see cancer-associated VTE.

A limitation of this survey is the low response rate (5.9\%), which is lower than the usual rate for oncology surveys [32]. The survey results might therefore not be representative, but they are still hypothesis generating. One explanation might be that members of these organizations who work in research, in health administration, or in other fields not involved in daily patient care did not respond. It is also possible that prophylaxis and treatment of VTE is not perceived as a primarily hemato-oncological problem but that it is more of an issue for general internists or family physicians, or some cancer specialists did not feel competent in issues of hemostasis and therefore did not answer. With 275 completed questionnaires, this is still the largest survey on the management of cancer-associated VTE in Germany. Almost $50 \%$ of the respondents had started to practice medicine before 1990 and 60\% work in the ambulatory sector. These characteristics suggest that they were more likely to be senior physicians in charge of treatment decisions and not physicians still in training. This can be interpreted as a particular strength of this survey. 


\section{VTE Prophylaxis}

Guidelines recommend thromboprophylaxis for most patients with cancer throughout hospitalization. This recommendation has been extrapolated from studies in general internal medicine patients [2]. There is uncertainty whether really all hospitalized cancer patients should be offered prophylaxis. The recent American Society of Clinical Oncology (ASCO) guideline update reflects this discussion and concedes that there is inadequate support for routine thromboprophylaxis in cancer patients admitted for minor procedures or short chemotherapy infusion $[9,10]$. The discomfort with uniform thromboprophylaxis is also reflected in our survey. Almost one-third of the respondents do not routinely offer thromboprophylaxis to hospitalized cancer patients.

In ambulatory patients, guidelines advise against routine thromboprophylaxis except for selected high-risk patients. The results of this survey are again in line with this recommendation in that many hematologists/oncologists only offer prophylactic anticoagulation to ambulatory patients with pancreatic cancer or multiple myeloma, as recommended by the ASCO or the National Comprehensive Cancer Network (NCCN) [10, 11]. Some also provide prophylaxis for ambulatory lung cancer patients, as has been recommended by the International Society on Thrombosis and Haemostasis (ISTH) [8].

With regard to risk assessment, the respondents ranked a history of prior VTE highest, followed by performance status and tumor type. This is interesting because the Khorana score only utilizes the tumor type but not the other 2 criteria [1]. This might explain why only a minority of physicians use the Khorana score. More than $90 \%$ of the respondents stated that they would welcome another simple and more practical assessment tool.

\section{Patient Education}

Most cancer patients are nowadays treated as outpatients and usually receive specific instructions on what to do when side effects (e.g. fever) occur. One can assume that $100 \%$ of cancer patients undergoing chemotherapy have been told about the risk of infection because this is an integral part of all consent forms. In contrast, only $38 \%$ of hematologists/oncologists inform their patients routinely about signs and symptoms of VTE before starting cancer treatment. This percentage is surprisingly low considering how common thromboembolism is in cancer patients. Up to $8 \%$ of the ambulatory and $20 \%$ of the hospitalized cancer patients develop VTE $[1,2]$. This number is comparable to the incidence of febrile neutropenia, and thromboembolism is a leading cause of death in cancer outpatients receiving chemotherapy [33]. Therefore, the ASCO 2013 guideline for the first time explicitly recommended that oncology professionals educate their patients about the signs and symptoms of VTE [9]. Apparently, the oncology community does not yet perceive VTE as an essential complication of cancer and thus an integral part of patient education, at least not as essential as neutropenic fever or infections. This misjudgment needs to be amended.

\section{Diagnosis and Initial Treatment}

Most respondents in this survey stated that they see 1 or more patients with cancer-associated VTE per month. Symptoms usually trigger diagnostic workup, but physicians also report a high number of incidental VTEs in their cancer patients. This may be explained by the frequent diagnostic imaging in cancer patients for reasons other than deep-vein thrombosis (DVT) or pulmonary embolism (PE) [34].

For initial treatment, most of the respondents give LMWH, which is in accordance with guideline recommendations. However, almost one-fifth switches to oral anticoagulants already during this initial treatment phase. We did not query the reasons for this deviation from the guideline recommendations, but we may speculate that convenience of oral anticoagulation is an important factor [30].

\section{Secondary Prophylaxis}

We wanted to know who is in charge of secondary prophylaxis for cancer-associated VTE after the initial phase. $69 \%$ of the physicians responded that they stay in charge of treatment. At the same time, 54\% stated that they transfer treatment to the family physician or another specialist (the sum is $>100 \%$ because some respondents marked both options). Again, we did not query the specific reasons, but the following scenarios are possible:

Cancer patients with VTE are initially treated as inpatients, and after discharge from the hospital, they first go to see their family physician who then continues VTE treatment.

Many VTE patients might be too sick to receive any further cancer-specific therapy and are managed by their family physician or specialized palliative care physicians and no longer by their hematologist/oncologist.

Another reason might be that, in Germany, hematologists/oncologists receive a fixed lump sum payment for every cancer patient. Additional office visits for treatment and monitoring of VTE do not generate additional revenues. It is therefore attractive to transfer the VTE care to the family physician or another specialist.

Whatever the reason, it shows that cancer patients see different doctors for closely related medical problems. It is therefore important to disseminate knowledge on the prophylaxis and treatment of cancer-associated VTE not only among hematologists/ oncologists but among all physicians involved in the care of these patients.

Most of the respondents give secondary prophylaxis for 3 months or longer employing LMWH, 37\% of them with $100 \%$ therapeutic dose; some reduce to $75 \%$ of the initial therapeutic dose and $40 \%$ stated that they even reduce to $50 \%$. Most physicians reduce the heparin dose after 3 months or later (table 5). Again, we did not query the reasons, but from the authors' experience, several scenarios are likely:

Many patients have initially received therapeutic LMWH as twice daily (BID) injections (e.g., in Germany, therapeutic-dose enoxaparin is licensed only for BID administration), and it is more convenient to give only 1 injection. 
A dose reduction to $75 \%$ of the initial dose for secondary prophylaxis after the acute phase is recommended for cancer-associated VTE treated with dalteparin. It is possible that many physicians follow the same approach when they use other LMWHs although this dose reduction has only been tested for dalteparin. Still, neither dalteparin nor any of the other LMWHs has an approval for $50 \%$ (half-therapeutic) dosing.

The risk of recurrent thrombosis is perceived as highest during the first 3 months, and lower thereafter [35]. Therefore oncologists may find a half-therapeutic dose more acceptable after 3 months.

Oncology professionals are concerned about the risk of bleeding because this is significantly higher in cancer than in non-cancer patients. Half-therapeutic dosing 'feels' safer.

Regimens with a dose intermediate in anticoagulant intensity between high- and low-dose regimens (half-therapeutic dose) are commonly used for perioperative bridging of non-cancer patients, and many physicians have personal experience with half-therapeutic dosing [36, 37].

In this survey, $55 \%$ of the respondents stated that they would continue LMWH for secondary prophylaxis. But $31 \%$ stated that they would also give VKAs, and 33\%, NOACs (again some of the respondents marked 2 or all 3 options). In the 2003 FRONTLINE survey, $66-88 \%$ of the respondents switched to oral anticoagulants [18]. Thus, the guideline recommendations have achieved some change, but the high percentage of VKA/NOAC use is still surprising. One has to keep in mind that, at the time of this survey, rivaroxaban was the only NOAC approved for VTE treatment (market approval in Germany in December 2011). Within 2 years of market introduction, already one-third of the physicians felt comfortable with giving these agents to oncology patients, despite the fact that there are no studies showing the efficacy and safety of NOACs in cancer patients in a head-to-head comparison with LMWH. In addition, NOACs might interfere with anticancer agents [38]. An important reason could be that VTE treatment with NOACs is almost 4 times cheaper than with LMWH. While the German health care system covers all medications, it also urges the physicians to choose the most cost-effective treatment. Most practices have a cap on prescription costs, and in the daily practice, cost considerations factor into treatment decisions.

Another common argument is that VKAs and NOACS have market approval for all patients with VTE and that cancer patients are not excluded from this approval. From a medicolegal standpoint, it is therefore 'safe' to prescribe VKAs or NOACs to cancer patients. This discrepancy between market approval and guideline recommendations underlines the urgent need for more studies on anticoagulation in cancer patients.

\section{Long-Term Treatment beyond 6 Months}

Prospective trials of anticoagulation in cancer patients beyond 6 months are rare [39], but long-term anticoagulation is recommended by most guidelines, at least when cancer is still present. $69 \%$ of the respondents offer long-term anticoagulant treatment to their patients with active cancer. For this long-term treatment beyond the initial 6-12 months, oral agents are preferred over LMWH.

We asked which reasons are considered relevant in deciding for or against LMWHs, VKAs, or NOACs. In case of LMWH, practical issues like the need for injections and the availability of a partner to perform injections ranked highest. This suggests that the capability of cancer patients to accept long-term injectable anticoagulant treatment is probably underestimated. Studies have shown that injections are per se no barrier to good compliance [40]. Patients with cancer-associated VTE are much more willing to continue long-term injections, as long as this does not interfere with their cancer treatment $[41,42]$. In case of VKAs, the need for INR measurements and the fear of bleeding were important factors. Fear of bleeding was also important with NOACs. This is not surprising because cancer patients have a particularly high bleeding rate, and at the time of this survey, no antidote was available. Another issue with NOACs was the number of comedications. This is important not only because of potential interactions between NOACs and anticancer agents but also because oncologists are very aware of decreasing adherence when they prescribe more oral medications [43].

In conclusion, this study shows that prophylaxis and initial treatment of VTE in cancer patients follows guideline recommendations while secondary prophylaxis and long-term therapy varies substantially. Economic and convenience factors may play a major role in treatment decisions. Patients with cancer-associated VTE are managed not only by their hematologist/oncologist but also by family physicians and other specialists. Our survey underlines the need to disseminate knowledge of and improve adherence to guidelines on the treatment of cancer-associated VTE among all physicians who participate in the care of cancer patients.

\section{Acknowledgements}

The authors would like to thank Sven Bischoff, Charité Universitätsmedizin Berlin, for data analysis. The authors would also like to thank the DGHO (Deutsche Gesellschaft für Hämatologie und medizinische Onkologie) and the DGP (Deutsche Gesellschaft für Phlebologie), who distributed the questionnaires electronically to all their members. 


\section{Disclosure Statement}

This survey was funded by LEO Pharma GmbH, Neu-Isenburg. LEO Pharma had no role in data analysis and in the decision to present and publish this manuscript.

A.M.: Stockownership: Roche, Bayer; speaker's honoraria and travel expenses: AMGEN, Aspen Germany, Boehringer Ingelheim, Behring, LEO Pharma, consultant: AMGEN, GlaxoSmithKline, Baxter, LEO Pharma,
Boehringer Ingelheim, Bristol-Myers Squibb, GlaxoSmithKline, LEO Pharma, Roche. Institution received research funding from LEO Pharma. B.L.: Employee LEO Pharma. M.S.: Speaker's honoraria from Bauerfeind and research funding from Bayer. H.R.: Consultant: Bayer, Boehringer Ingelheim, BMS, Daiichy-Sankyo, LEO Pharma; speaker's honoraria: Bayer, Boehringer Ingelheim, BMS, Daiichy-Sankyo, LEO Pharma, Novartis, Pfizer, Sanofi-Aventis.

\section{References}

1 Khorana AA, Kuderer NM, Culakova E, Lyman GH, Francis CW: Development and validation of a predictive model for chemotherapy-associated thrombosis. Blood 2008;111:4902-4907.

2 Carrier M, Khorana AA, Moretto P, Le Gal G, Karp R, Zwicker JI: Lack of evidence to support thromboprophylaxis in hospitalized medical patients with cancer. Am J Med 2014;127:82-86.

3 Gil-Bernabé A, Lucotti S, Muschel RJ: Coagulation and metastasis: what does the experimental literature tell us? Br J Haematol 2013;162:433-441.

4 Lin RJ, Afshar-Kharghan V, Schafer AI: Paraneoplastic thrombocytosis: the secrets of tumor self-promotion. Blood 2014;124:184-187.

5 Sørensen HT, Mellemkjær L, Olsen JH, Baron JA: Prognosis of cancers associated with venous thromboembolism. N Engl J Med 2000;343:1846-1850.

6 Chew HK, Wun T, Harvey D, Zhou H, White RH: The incidence of venous thromboembolism and its effect on survival among patients with common cancer. Arch Intern Med 2006;166:458-464.

7 Kuderer NM, Ortel TL, Francsi CW: Impact of venous thromboembolism and anticoagulation on cancer and cancer survival. J Clin Oncol 2009;27:4902-4911.

8 Farge D, Debourdeau P, Beckers M, Baglin C, Bauersachs RM, Brenner B, Brilhante D, Falanga A, Gerotzafias GT, Haim N, Kakkar AK, Khorana AA, Lecumberri R, Mandala M, Marty M, Monreal M, Mousa SA, Noble S, Pabinger I, Prandoni P, Prins MH, Qari MH, Streiff MB, Syrigos K: International clinical practice guidelines for the treatment and prophylaxis of venous thromboembolism in patients with cancer. J Thromb Haemost 2013;11:56-70.

9 Lyman GH, Khorana AA, Kuderer NM, Lee AY, Arcelus JI, Balaban EP, Clarke JM, Flowers CR, Francis CW, Gates LE, Kakkar AK, Key NS, Levine MN, Liebman HA, Tempero MA, Wong SL, Prestrud AA, Falanga A; American Society of Clinical Oncology Clinical Practice: Venous thromboembolism prophylaxis and treatment in patients with cancer: American Society of Clinical Oncology clinical practice guideline update. J Clin Oncol 2013;31:2189-2204.

10 Lyman GH, Bohlke K, Khorana AA, Kuderer NM, Lee AY, Arcelus JI, Balaban EP, Clarke JM, Flowers CR, Francis CW, Gates LE, Kakkar AK, Key NS, Levine MN, Liebman HA, Tempero MA, Wong SL, Somerfield MR, Falanga A; American Society of Clinical Oncology: Venous thromboembolism prophylaxis and treatment in patients with cancer: American Society of Clinical Oncology clinical practice guideline update 2014. J Clin Oncol 2015;33:654-656.

11 NCCN Clinical Practice Guidelines in Oncology. Cancer-associated venous thromboembolic disease. Version 1/2014, www.nccn.org [last accessed January 7, 2016].

12 Hull RD, Pineo GF, Brant RF, Mah AF, Burke N, Dear R, Wong T, Cook R, Solymoss S, Poon MC, Raskob G; LITE Trial Investigators: Long-term low-molecularweight heparin versus usual care in proximal-vein thrombosis patients with cancer. Am J Med 2006;119: 1062-1072.
13 Meyer G, Marjanovic Z, Valcke J, Lorcerie B, Gruel Y, Solal-Celigny P, Le Maignan C, Extra JM, Cottu P, Farge $\mathrm{D}$ : Comparison of low-molecular-weight heparin and warfarin for the secondary prevention of venous thromboembolism in patients with cancer: a randomized controlled study. Arch Intern Med 2002;162:1729-1735.

14 Lee AY, Levine MN, Baker RI, Bowden C, Kakkar AK, Prins M, Rickles FR, Julian JA, Haley S, Kovacs MJ, Gent M; Randomized Comparison of Low-Molecular-Weight Heparin versus Oral Anticoagulant Therapy for the Prevention of Recurrent Venous Thromboembolism in Patients with Cancer (CLOT) Investigators: Low-molecular-weight heparin versus a coumarin for the prevention of recurrent venous thromboembolism in patients with cancer. N Engl J Med 2003;349:146-153.

15 Deitcher SR, Kessler CM, Merli G, Rigas JR, Lyons RM, Fareed J; ONCENOX Investigators: Secondary prevention of venous thromboembolic events in patients with active cancer: enoxaparin alone versus initial enoxaparin followed by warfarin for a 180-day period. Clin Appl Thromb Hemost 2006;12:389-396.

16 Caprini JA, Tapson VF, Hyers TM, Waldo AL, Wittkowsky AK, Friedman R, Colgan KJ, Shillington AC; NABOR Steering Committee: Treatment of venous thromboembolism: adherence to guidelines and impact of physician knowledge, attitudes, and beliefs. J Vasc Surg 2005;42:726-733.

17 Schellong SM, Gerlach H, Hach-Wunderle V, Rabe E, Riess H, Carnarius H, Eberle S, Bauersachs R: Diagnosis of deep-vein thrombosis: adherence to guidelines and outcomes in real-world health care. Thromb Haemost 2009;102:1234-1240.

18 Kakkar AK, Levine M, Pinedo HM, Wolff R, Wong J: Venous thrombosis in cancer patients: insights from the FRONTLINE survey. Oncologist 2003;8:381-388.

19 Wittkowsky AK: Barriers to the long-term use of lowmolecular weight heparins for treatment of cancerassociated thrombosis. J Thromb Haemost 2006;4: 2090-2091.

20 Imberti D, Agnelli G, Ageno W, Moia M, Palareti G, Pistelli R, Rossi R, Verso M; MASTER Investigators: Clinical characteristics and management of cancer-associated acute venous thromboembolism: findings from the MASTER Registry. Haematologica 2008; 93 : 273-278.

21 Wright JD, Lewin SN, Shah M, Burke WM, Lee SM, Sun X, Herzog TJ: Quality of venous thromboembolism prophylaxis in patients undergoing oncologic surgery. Ann Surg 2011;253:1140-1146.

22 Abdel-Razeq H, Albadainah F, Hijjawi S, Mansour A, Treish I: Venous thromboembolism (VTE) in hospitalized cancer patients: prophylaxis failure or failure to prophylax! J Thromb Thrombolysis 2011;31:107-112.

23 Spirk D, Ugi J, Korte W, Husmann M, Hayoz D, Baldi T, Frauchiger B, Banyai M, Aujesky D, Baumgartner I, Kucher N: Long-term anticoagulation treatment for acute venous thromboembolism in patients with and without cancer. The SWIss Venous ThromboEmbolism Registry (SWIVTER) II. Thromb Haemost 2011; 105:962-967.
24 Delate T, Witt DM, Ritzwoller D, Weeks JC, Kushi L, Hornbrook MC, Aiello Bowles EJ, Schrag D: Outpatient use of low molecular weight heparin monotherapy for first-line treatment of venous thromboembolism in advanced cancer. Oncologist 2012;17:419-427.

25 Marchena PJ, Nieto JA, Guil M, García-Bragado F, Rabuñal R, Boccalon H, Trujillo-Santos J, Monreal M; RIETE Investigators: Long-term therapy with lowmolecular-weight heparin in cancer patients with venous thromboembolism. Thromb Haemost 2012;107: 37-43.

26 Belhadj Chaidi R, Thollot C, Roblot P, Landron C: Adherence to guidelines for the treatment of venous thromboembolism in cancer patients: a retrospective analysis of 145 cases [Article in French]. J Mal Vasc 2013;38:185-192.

27 Kleinjan A, Hutten B, Di Nisio M, Büller HR, Kamphuisen PW: Anticoagulant treatment of cancer patients with pulmonary embolism in the real world. Actual use of low-molecular-weight heparin in cancer. Neth J Med 2014;72:467-472.

28 Rahme E, Feugère G, Sirois C, Weicker S, Ramos E: Anticoagulant use in patients with cancer-associated venous thromboembolism: a retrospective cohort study. Thromb Res 2013;131:210-217.

29 Sevestre MA, Belizna C, Durant C, Bosson JL, Vedrine L, Cajfinger F, Debourdeau P, Farge D; Carmen Investigators for the Groupe Francophone Thrombose et Cancer (GFTC): Compliance with recommendations of clinical practice in the management of venous thromboembolism in cancer: the CARMEN study. J Mal Vasc 2014;39:161-168.

30 Weitz JI, Gross PL: New oral anticoagulants: which one should my patient use? Hematology Am Soc Hematol Educ Program 2012;2012:536-540.

31 Wells PS, Anderson DR, Rodger M, Forgie M, Kearon C, Dreyer J, Kovacs G, Mitchell M, Lewandowski B, Kovacs MJ: Evaluation of D-dimer in the diagnosis of suspected deep-vein thrombosis. N Engl J Med 2003; 349:1227-1235.

32 Martins Y, Lederman RI, Lowenstein CL, Joffe S, Neville BA, Hastings BT, Abel GA: Increasing response rates from physicians in oncology research: a structured literature review and data from a recent physician survey. Br J Cancer 2012;106:1021-1026.

33 Khorana AA, Francis CW, Culakova E, Kuderer NM, Lyman GH: Thromboembolism is a leading cause of death in cancer patients receiving outpatient chemotherapy. J Thromb Haemost 2007;5:632-634.

34 Dentali F, Ageno W, Becattini C, Galli L, Gianni M, Riva N, Imberti D, Squizzato A, Venco A, Agnelli G: Prevalence and clinical history of incidental, asymptomatic pulmonary embolism: a meta-analysis. Thromb Res 2010;125:518-522.

35 Kearon C: A conceptual framework for two phases of anticoagulant treatment of venous thromboembolism. J Thromb Haemost 2012;10:507-511. 
36 Douketis JD, Spyropoulos AC, Spencer FA, Mayr M, Jaffer AK, Eckman MH, Dunn AS, Kunz R; American College of Chest Physicians: Perioperative management of antithrombotic therapy: antithrombotic therapy and prevention of thrombosis, 9th ed: American College of Chest Physicians evidence-based clinical practice guidelines. Chest 2012;141(2 suppl):e326Se350S.

37 Omran H, Bauersachs R, Rübenacker S, Goss F, Hammerstingl C: The HAS-BLED score predicts bleedings during bridging of chronic oral anticoagulation. Results from the national multicentre BNK Online bRiDging REgistRy (BORDER). Thromb Haemost 2012; 108:65-73.

38 Short NJ, Connors JM: New oral anticoagulants and the cancer patient. Oncologist 2014;19:82-93.
39 Francis CW, Kessler CM, Goldhaber SZ, Kovacs MJ, Monreal M, Huisman MV, Bergqvist D, Turpie AG, Ortel TL, Spyropoulos AC, Pabinger I, Kakkar AK: Treatment of venous thromboembolism in cancer patients with dalteparin for up to 12 months: the DALTECAN study. J Thromb Haemost 2015;13:10281035.

40 Bergqvist D, Arcelus JI, Felicissimo P; ETHOS Investigators: Post-discharge compliance to venous thromboembolism prophylaxis in high-risk orthopaedic surgery: results from the ETHOS registry. Thromb Haemost 2012;107:280-287.

41 Farge D, Debourdeau P, Gorin NC, Lamblin A, Cajfinger F: Long-term use of low-molecular-weight heparins (LMWH) for cancer-associated venous thromboembolism (VTE): patients' perception in Tropique, a prospective, multicenter, observational study. Blood 2014;124:abstr 4272.
42 Noble S, Matzdorff A, Maraveyas A, Holm MV, Pisa G: Assessing patients' anticoagulation preferences for the treatment of cancer-associated thrombosis using conjoint methodology. Haematologica 2015; 100:14861492.

43 Barthélémy P, Asmane-De la Porte I, Meyer N, Duclos B, Serra S, Dourthe LM, Amé S, Litique V, Giron C, Goldbarg V, Fornecker L, Quoix E, Kurtz JE: Adherence and patients' attitudes to oral anticancer drugs: a prospective series of 201 patients focusing on targeted therapies. Oncology 2015;88:1-8. 